\title{
ERRATUM
}

\section{Fungal Degradation of the Bioplastic PHB (Poly-3-hydroxy-butyric acid)}

\author{
K.-M. Lee · D. F. Gimore • M. J. Huss
}

Published online: 13 April 2006

(C) Springer Science+Business Media, Inc. 2006

J Polym Environ (2005) 13(3): 213-219

In the article by Lee et al., an author's name appeared incorrectly.

The list of authors appears correctly as follows:

K.-M. Lee, ${ }^{1,2,3}$ D. F. Gilmore, ${ }^{1}$ and M. J. Huss ${ }^{1}$

The online version of the original article can be found at http://dx.doi.org/10.1007/s10924-005-4756-4

K.-M. Lee $(\varangle)$ · D. F. Gilmore · M. J. Huss

Environmental Sciences Program, Arkansas State University,

Jonesboro, AR 72467, USA

E-mail: klee0922@yahoo.co.kr

Present address: K.-M. Lee

Manager/R\&D Center Celltrion, Inc., 1001-5 Dongchum-dong,

Yeonsu-gu, Inchen 406-130, Korea 